\title{
LA CONDICIÓN SOCIAL DEL PINTOR DE LA MODERNIDAD EN PARÍS EN LA SEGUNDA MITAD DEL SIGLO XIX
}

\author{
Mireia Ferrer Álvarez. \\ Universitat de València
}

Resumen: El presente artículo pretende profundizar desde la reflexión bibliográfica en las distintas prácticas acometidas por los pintores de la segunda mitad del siglo XIX así como en la consideración que gozaron en el imaginario social de la modernidad. El estudio se centra en la ciudad de París como capital artística y dirige, así mismo, una mirada hacia la presencia de algunos artistas españoles.

Palabras clave: Condición social, pintores, modernidad, París.

The social condition of the painter of modernity in Paris in the second half of the nineteenth century

Abstract: The aim of the present paper is to deepen from the bibliographical reflection into the various practices undertaken by painters in second half of nineteenth-century as well as on the consideration that deserved from the social imaginary of modernity. The study focuses in the city of Paris as artistic capital and directs, as well, a regard toward the presence of some Spanish artists.

Key words: Social condition, painters, modernity, Paris.

\section{INTRODUCCIÓN}

La segunda mitad del siglo XIX experimenta en buena parte de las ciudades del ámbito europeo dos procesos: la conformación del modelo social urbano y la consolidación del sistema capitalista. En esos dos procesos los sujetos adoptan nuevos roles, adquieren nuevas prácticas o por el contrario mantienen o transforman ciertos rasgos que los identifican con sujetos históricos de otros periodos, constituyendo tipologías que oscilan entre lo sincrónico y lo diacrónico.

Los pintores como sujetos sociales fueron evolucionando a lo largo de la historia desde su inicial consideración como artesanos hasta la propia de la sociedad capitalista como creadores, aspecto que se aborda en las primeras páginas de este trabajo, en el epígrafe "la condición social".

El siguiente enfoque del estudio constituye una mirada hacia los modelos de pintor y su proyección en el imaginario colectivo decimonónico en la capital artística del momento, París. Se analizan tres modelos: el pintor bohemio, el pintor cosmopolita y el pintor comercial. Respecto al primero de ellos, el pintor bohemio, podríamos atribuirle un creciente protagonismo en el arte moderno, protagonismo, que fue paralelo a los procesos de erosión que la institución oficial artística de la Academia sufrió durante las tres últimas décadas del siglo XIX. Así mismo, el pintor bohemio ejemplifica a la perfección las prác-

Data de recepció: 14 d'abril de 2015 / Data d'acceptació: 22 de juny de 2015. 
ticas de atracción y negación propias de las sociedades burguesas decimonónicas, pues si bien manifiestan un profundo rechazo hacia la sociedad burguesa de la cual se enajenan, no es menos reseñable el hecho que la mayoría de ellos proviniesen de dicha extracción social. Ejemplo de artista vocacional, en el imaginario de entonces y en el posterior también, el pintor bohemio se muestra ligado a unas prácticas quasi performáticas y a unos espacios de sociabilidad propios.

El pintor cosmopolita, por su parte, se enmarca en la esfera de una estudiada semiótica de la proyección social, su estudio es la prolongación de su personalidad, su posición social se fundamenta en el establecimiento de redes clientelares que anticipan algunos modelos de comportamiento semejantes a las prácticas desarrolladas en las sociedades líquidas posmodernas. Por último, el pintor comercial se apropia de los nuevos sistemas de producción para concebir un arte con gran poder de atracción de público y económicamente muy sustancioso, sin embargo, este modus operandi contó con numerosos detractores, la crítica artística y las instituciones oficiales consideraron la práctica comercial de la pintura como una trasgresión de los principios e ideales artísticos, aunque los argumentos que esgrimieran unos $\mathrm{u}$ otros fueran muy distintos.

Toda esta cartografía artística conforma los trazos de una sociedad en la que el arte moderno experimentó una transformación (Polany, 1981) sin solución de retorno.

\section{LA CONDICIÓN SOCIAL}

S'attacher à la condition "sociale de l'artiste", c'est vouloir saisir le milieu, les circonstances matérielles, les facteurs économiques mais aussi personnels, par rapport auxquels un artiste a pu construire son identité sociale et produire des oeuvres réputées artistiques (La Gorce, 1985, 9).

Al aludir a la condición social del artista la historiografía artística se refiere al modelo de representación que el artista desempeñó en la sociedad, esto es, la consideración social e ideológica que proyectaron los miembros de una sociedad determinada sobre la figura del artista; algo que no debe confundirse con el estatus social del artista vinculado al ordenamiento jurídico administrativo de un periodo histórico determinado. En ocasiones, sin embargo, la relación entre ambos aspectos ha estado estrechamente imbricada.

Preguntarse sobre los mecanismos de construcción identitaria del artista en la sociedad, sobre los modelos de proyección social, nos llevaría a preguntarnos sobre la importancia del artista en el cuerpo social. Ya en 1941 el teórico de la arquitectura Sigfried Giedion abría uno de los capítulos de su archiconocida obra Espacio, Tiempo y arquitectura con la siguiente pregunta: Entonces, ¿realmente seguimos necesitando a los artistas? ${ }^{1}$.

En definitiva, preguntarse sobre la condición social del artista significa preguntarse sobre el enorme valor que los seres humanos reconocemos al acto creativo de todos los misterios del universo, ninguno más profundo que el de la creación (Zweig, 2008, 11). De todo ello se desprende el enorme interés que la figura del artista ha despertado en el imagi-

${ }^{1}$ En cualquier civilización, la sensibilidad continúa infiltrándose en todas las actividades y situaciones. Un ambiente cuyos principales aspectos resulten impenetrables para la sensibilidad es tan insatisfactorio como otro que se resista a un control práctico o intelectual (Giedion, 2009, 428-429). 
nario colectivo, y desde ahí, su traslación a la historiografía artística. Las historias que se cuentan sobre los artistas en todos los tiempos y latitudes reflejan una respuesta humana y universal a la magia misteriosa de la creación de una imagen (Kris y Kurz, 2002, 13).

De entre todos los periodos históricos dos han concentrado la mayoría de los estudios relativos a la condición social del artista, el Renacimiento y el siglo XIX. El tránsito de la figura de artesano a artista acometido en los siglos XV y XVI se manifestó como un fenómeno que trastocó las viejas prácticas del arte y condicionó las nuevas, al tiempo que contribuyó a crear una nueva consideración del artista en sociedad. La promoción de la Natura frente al Ars o la Exercitatio contribuyó a otorgar al artista esa cualidad que convirtió, tal y como Durero definió, a los artistas en alter deus, conformando toda una mitología en torno a la figura del artista de la que incluso hoy no es difícil desprendernos. Esta imagen ennoblecida del artista del Renacimiento ha pervivido en el imaginario colectivo a pesar que la realidad histórica en la que se gestó pudo ser otra bien diferente ${ }^{2}$. Tampoco se trató de un fenómeno homogéneo pues la elevación del artesano a artista no se manifestó de igual manera en los diferentes espacios geográficos de la vieja Europa, el propio Durero se lamentaba y hacía notar la enorme diferencia que mediaba en la consideración social de los artistas en Italia y en su Alemania natal: Combien je vais regretter le soleil, ici je suis un gentilhomme et chez moi un parasite (La Gorce, 2005, 18). Una suerte de differentia specifica que se pondrá nuevamente de manifiesto en las prácticas sociales que el hombre decimonónico desarrollará sobre la figura del artista, según distintos ámbitos geográficos.

La tratadística del Renacimiento no fue ajena a la transformación que el artista y, por ende, su consideración social estaba experimentando, en dichos tratados, la mayoría de ellos realizados por artistas en sí mismos, se establecieron modelos y hábitos que el nuevo pintor o escultor, elevado en su categoría profesional y reconocido socialmente, debía acometer. A las recomendaciones de maneras cortesanas: perfumarse, evitar las manchas de pintura en las manos y la camisa, comportarse sin afectación, pero con afabilidad y cortesía (Pino, 1954), se unían los consejos para evitar la vida desordenada y bohemia, a la que Vasari se refería como "vivere alla filosfica"3, en relación a la figura de Sócrates al que se considera primer bohemio de la historia. Vasari condenaba dicho régimen de vida por encima de todas las cosas. Así mismo el ideal académico alejará al artista de otro de sus grandes conflictos, el económico, Non sia il pittore dispettoso nell'essere premiato, ma si condanni, come quello che più apprezza l'onore che l'utile e aborrisca quel far mercato, caso veramente vilissima (Pino, 1954, 35).

En cierta medida la codificación de los modos y prácticas de los artistas del Renacimiento, estaban anunciando ya las propias que los pintores en el siglo XIX, contribuirán a perpetuar, a saber, la del artista bohemio, el artista comercial y el artista cosmopolita.

${ }^{2}$ La Italia del Quattrocento, $i$ àdhuc la del Cinquecento [...] És certament el primer i seriós pas cap a un canvi radical en la situació social de l'artista, però només en qualitat d'inici. No tenim xifres estadístiques a la mà, però estic convençut que, exepció feta dels grans mestres (els alter deus, segons Kris $i$ Kurz) un $90 \%$ dels artistes italians dels segles XV i XVI van viure estrictament com a artesans (Company, 1991, 27).

${ }^{3}$ Ma quello che era cosa, non so se degna di riso o di compassione, egli era d'una compagnia d'amici, o piuttosto masnada, che sotto nome di vivere alla filosfica viveano come porci e como bestie; non si lavavno mai nè mani nè viso nè capo né barba, non spazzavano la casa, e non rifaccevano il letto, se non ogni due mesi una volta, apparecchiavano con i cartoni delle pitture le tavole, e nonbeveano se non al fiasco ad al boccale; e questa loro meschinità, e vivere, come si dice, alla carlona, era da loro tenuta la più bella vita del mondo (Vasari, 1832-1838, 868). 


\section{EL PINTOR DEL SIGLO XIX}

No es posible abordar el estudio de las prácticas y la condición social de los pintores de la modernidad en la segunda mitad del siglo XIX sin atender a dos procesos de trascendental incidencia en el arte de ese mismo periodo, en primer lugar la paulatina transformación del valor de uso en valor de cambio que había experimentado el arte, un proceso que se había iniciado en el siglo XVII pero que cristaliza en el siglo XIX con el advenimiento del sistema capitalista, en segundo lugar y, como causa o consecuencia, la conformación del mito del artista como ser excepcional dotado de la capacidad atribuida al genio, que nace con la idealización del Romanticismo. Resulta evidente en efecto que, como siempre ocurre, los factores llamados morfológicos están a su vez subordinados a condiciones sociales como, en este caso particular, el enorme prestigio de las grandes carreras de pintor o de escritor (Bourdieu, 1995, 89-90).

En ese proceso de sublimación hacia la figura del artista juegan un papel determinante las propias obras artísticas ${ }^{4}$. La conformación del artista en el imaginario colectivo del siglo XIX debe tanto a la contribución de la literatura decimonónica como a la propia existencia del modelo al cual hacía alusión, en un diálogo en el que los modelos se articulan indisociablemente. Un modelo, el de las prácticas representacionales, que tal y como plantearon los historiadores de la cuarta generación de L'Ecole d'Annales, con Roger Chartier a la cabeza, se establecía como una herramienta que ofrecía a los historiadores la posibilidad de articular las representaciones colectivas que fundamentan para cada comunidad, las maneras de percibir, clasificar y juzgar. Maneras que emanan de las formas simbólicas gracias a las cuáles los poderes, los grupos o los individuos proponen una imagen de ellos mismos (Chartier, 2002).

Efectivamente, en el proceso de construcción de los modelos culturales, como se refiere Bourdieu, el productor intelectual bajo la apariencia de decir lo que es, aspira a hacer ver y hacer creer (Bourdieu, 1995, 92). Debemos atribuir, por tanto, una enorme influencia en la consideración del artista del siglo XIX, a obras como La educación sentimental de Gustave Flaubert, Escenas de la vida Bohemia de Henry Murguer o La obra de Émile Zola, entre otras muchas; de la misma manera que determinadas obras plásticas se configuran a modo de arquetipos: Interior de estudio de Octave Tassaert ${ }^{5}$, los retratos que los pintores catalanes Santiago Rusiñol y Ramón Casas realizaron sobre Erik Satie $^{6}$, o los retratos fotográficos de John Singer Sargent o Joaquín Sorolla, contribuyeron igualmente, a conformar modelos que todavía hoy permanecen en nuestro imaginario.

En 1899 el redactor de las crónicas en París de la revista española La Ilustración artística exponía en su artículo dedicado al certamen del Salón de Bellas Artes de ese mismo año, un personal retrato de los tipos de artistas que habitaban la capital, un atlas humano

${ }^{4}$ Las representaciones siempre se analizan como síntomas de causas externas a ellas mismas (el sexismo, el patriarcado, el capitalismo, el racismo...) en vez de intentar comprender el papel activo que cumplen en la construcción de esas mismas categorías (Mayayo, P., 2003, p. 174).

5 Octave Tassaert. Interior de estudio. 1845. Óleo/lienzo, 46 x 38 cm. Museo del Louvre.

${ }^{6}$ Santiago Rusiñol. Erik Satie tocando el harmonium. 1891. Lápiz/ papel, 29’2 x 19’7 cm. Museu Nacional d'Art de Catalunya; Santiago Rusiñol. Un bohemio, Erik Satie en su estudio. 1891, Óleo/lienzo. 85 × 67 cm. Archivo Joan Maragall. Generalitat de Catalunya; Ramón Casas. El bohemio. 1891. Óleo/ lienzo, 200 x $100 \mathrm{~cm}$. Northwestern University Library. 
de los artistas, porque tal y como indicaba sólo en París pueden señalarse diversas categorías perfectamente distintas entre los que se titulan artistas (X., 1899, 911, 379).

El primer grupo lo conformaban según este cronista los apasionados [...] viven por el arte tal como ellos lo comprenden, procurando unos formar escuela mediante la propaganda de sus ideas, encerrados otros dentro de sí mismos, trabajando asiduamente en silencio y nunca satisfechos del resultado obtenido en comparación del que quisieron alcanzar (X., 1899, 911, 379).

\section{PARÍS BOHÈME}

No se presenta como algo sencillo establecer los límites que definían la vida bohemia. No en vano uno de los primeros historiadores del Arte en abordar esta cuestión, Arnold Hauser (Hauser [1951], 2009), tuvo que establecer tres categorizaciones distintas que respondían a tres generaciones, con hábitos y prácticas diferentes. Y fundamentalmente porque como apuntaba Jerrold Seigel (Seigel, 1991) muchos de los comportamientos asignados a los bohemios se pueden hallar también en círculos sociales fuera de la bohemia y viceversa.

Durante la primera mitad del siglo XIX la bohemia fue relacionada directamente con los sectores más marginales de la sociedad, con la delincuencia y los desclasados. Esta vinculación estaba directamente determinada por el sistema de ordenamiento jurídico que la propia sociedad francesa contaba en ese momento. Un rígido sistema que codificaba la población en virtud de los états u ocupaciones legales, de tal modo que todas aquellas ocupaciones que no podían ser consideradas états ${ }^{7}$ no eran legales y, por tanto, pasaban a formar parte de la ilegalidad y la mendicidad. Este sistema era del todo pernicioso para la vida errante y bohemia, ya que se hacía bastante complicado probar una dedicación profesional a seres con domicilio itinerante y dedicaciones diversas. La imposibilidad de ser reconocidos por el desempeño de la profesión artística les colocaba en el límite de la legalidad, carentes de un estatuto civil reconocido. Ce pouvaient être des génies méconnus ou des escrocs: l'appellation de "bohèmes" les situait dans une zone crépusculaire entre l'ingéniosité et la criminalité (D’Ennery y Grangé, 1843, 8-9).

Sin embargo, a medida que se fue extendiendo el desarrollo de la práctica artística, fenómeno al que Félix Pyat bautizó como épidemie d'artistisme ${ }^{8}$ la consideración social de la bohemia en París fue transformándose, pasando a conformar un atractivo para la propia ciudad que observaba con orgullo como en su hegemonía de capitalidad los artistas bohemios, junto a los artistas oficiales, ejercían un enorme poder de atracción. D'autres villes avaient leur lot de déclassés, d'excentriques et d'irréguliers. Mais il n'y avait que París pour les traiter avec pareille considération (Seigel, 1991, 231).

La bohemia estaba poblada mayoritariamente por hombres jóvenes ${ }^{9}$, aunque quizás el

\footnotetext{
7 Algunas ocupaciones, no obstante, que escapaban a las clasificaciones profesionales obtuvieron una nueva categoría conocida como "métiers nouveaux o inconnues".

${ }^{8}$ Aujourd'hui, tous se disent artistes: princes, criminels, inventeurs, tous ceux qui touchent la main de Victor Hugo, artistas [...] On est artiste comme on était propriétaire, c'est la qualité de celui qui n'en a pas (Pyat, 1834, 1-21).

9 Cabría preguntarse, no obstante, si no debiera hacerse una revisión de género e incluir en esta categoría a personajes de la vida artística parisina bohemia como Suzanne Valladon o Madeleine Boisguilaume, entre otras, a las que la construcción histórica tradicional ha excluido. De alguna manera la figura del
} 


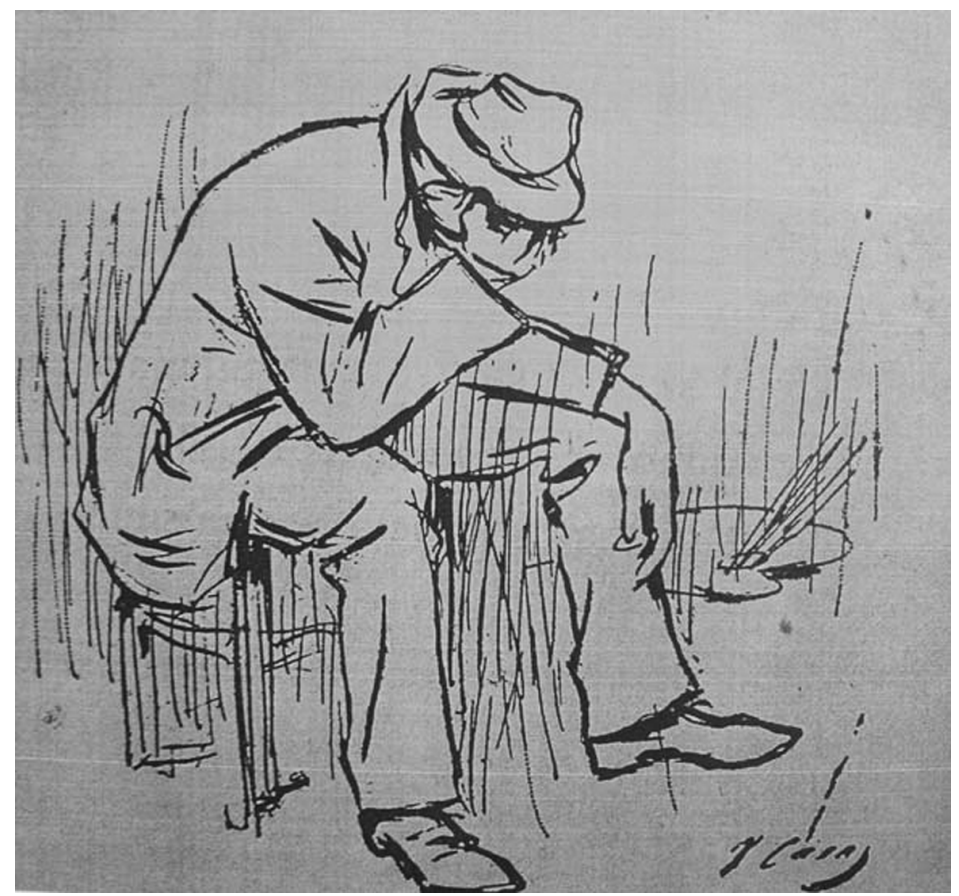

Fig. 1. Ramón Casas, Un pintor puntillista de Montmartre. Dibujo. "Desde el Molino. El estudio de un puntillista", La Vanguardia, 25-12-1890, 4.

aspecto más significativo fuera el de su extracción social. Una extracción que los relacionaba directamente con la burguesía y sus conflictos de clase. ${ }^{10}$

Efectivamente, uno de los rasgos más característicos que conformaron los hábitos del hombre moderno en la gran urbe fue el de la teatralización como práctica social. La ciudad deviene un gran escenario en el que los sujetos escenifican, contemplan y representan a un mismo tiempo (Schwartz, 1999). Es en ese sentido que la teatralización de la práctica de la vida bohemia por parte de individuos cuyos recursos económicos les hubieran permitido vivir holgadamente, para pasar a vivir en condiciones miserables, constituya uno de los rasgos más representativos de la esencia de un nutrido sector de la bohemia parisina decimonónica.

\footnotetext{
bohemio como la del genio o la del dandy son construcciones masculinas carentes de versión femenina, por más que algunas artistas hayan querido subvertirlas como hiciera la pintora norteamericana Romaine Brooks en su autorretrato de 1923.

${ }^{10}$ La bohème n'était un domaine étranger à la vie bourgeoise, mais l'expression d'un conflit surgit dans son sein même [...] surgit à l'intersection de l'action et de la signification, du geste et de la conscience. Elle était à la fois un genre de vie et une interprétation théâtrale, et d'elle-même et de la société contre laquelle elle réagissait (Seigel, 1991, 15-22).
} 
Y quizás podamos reconocer en las palabras que le dedica Santiago Rusiñol a su amigo muerto, fallecido por complicaciones pulmonares consecuencia de un precario régimen de vida bohemio, el pintor Ramón Canudas, un atisbo de culpabilidad, pues según Rusiñol, Canudas fue un bohemio sin elección (Rusiñol, 1892, 4-5).

La loi de l'incognito (Murguer, 1988, 34), como definía Murguer a los artistas que no habían hallado reconocimiento, y un destino trágico, se constituían como preceptos de un inmenso sector de la bohemia. Tal y como hizo Zola en La Obra, al ilustrar a Claude Lantier un pintor con un triste final, personaje inspirado en el pintor Jules Holtzaptel, quien se suicidó de un disparo de revolver al saber que sus pinturas habían sido rechazadas por el jurado del Salón de 1866.

Entre la vocación y la representación de un modo de vida, al que se podía descender para luego tornar a una vida respetable, se situó ese heterogéneo grupo social que denominamos bohemia, quizás por eso Émile Goudeau el maestro de ceremonias y fundador del cenáculo bohemio, el café de Les Hydropathes, alertaba: Frères! Il faut bifurquer à temps (Golfier y Wagneur, 2000, 262).

\section{PINTOR COSMOPOLITA ${ }^{11}$}

Una fotografía nos traslada al número 41 del boulevard Berthier de París (Fig. 2), es 1884, hayamos a un hombre vestido de etiqueta inmerso en un universo ligado indisolublemente a la figura del artista, el estudio. La imagen despliega todo su poder evocativo y proyecta un mensaje que descodificamos en forma simbólica.

Hacía más de tres siglos, en 1498, Alberto Durero ${ }^{12}$, se autorretrataba como un gentilhombre, seguro de sí mismo, pudiera decirse arrogante, vestido con ropas lujosas y guantes de piel que denotaban un estatus social y económico. Efectivamente, se ha venido reconociendo este autorretrato como el símbolo iconográfico del proceso de ennoblecimiento del artesano a artista acometido en esos siglos del Renacimiento, la construcción de la imagen del artista del Renacimiento se enmarca ya en un estudiado proceso representacional, una estética de la existencia (Foucault, 2003) en la que arte, artista y vida se entrecruzan.

Algo similar puede ser observable en la fotografía de John Singer Sargent. La escenografía del estudio está dispuesta para proyectar esa imagen del pintor cosmopolita y chic, como una suerte de prolongación de su persona. Esta semiótica de los objetos y de la construcción del yo, nos acerca a esa figura del pintor.

Sargent aparece en su estudio con la mirada esquiva, vestido con traje. Los cortinajes, símbolo totémico del artificio en el estudio del pintor adquieren una enorme presencia ${ }^{13}$.

11 Sous la forme nouvelle, l'Académie avait fait accéder le peintre à une position sociale qui n'avait jamais été aussi élevée. Elle lui accordait le statut d'homme de savoir, faisant de lui l'égal des philosophes et des hommes de lettres des autres sections de l'Institut (White, 1992, 38).

12 Alberto Durero. Autorretrato. 1498. Óleo/tabla, 53 x $41 \mathrm{~cm}$. Museo del Prado.

13 Las cortinas a lo largo de la historia han estado ligadas a la idea del arte como engaño o artificio, una relación que proviene de la anécdota de las uvas de Parrasio y Zeuxis contada por Plinio, y que se refiere así: Zeuxis pintó unas uvas y algunos gorriones acudieron a picotearlas. Entonces, Parrasio le rogó que le acompañase a su estudio, donde le mostraría que también él podía hacer algo similar. Una vez allí, Zeuxis pidió a Parrasio que descorriese la cortina que cubría la pintura. Pero la cortina era una pintura. Así Zeuxis admitió la superioridad de Parrasio diciendo: yo engañé a los gorriones, pero he sido engañado por ti (Kris y Kurz, 2002, 64). 


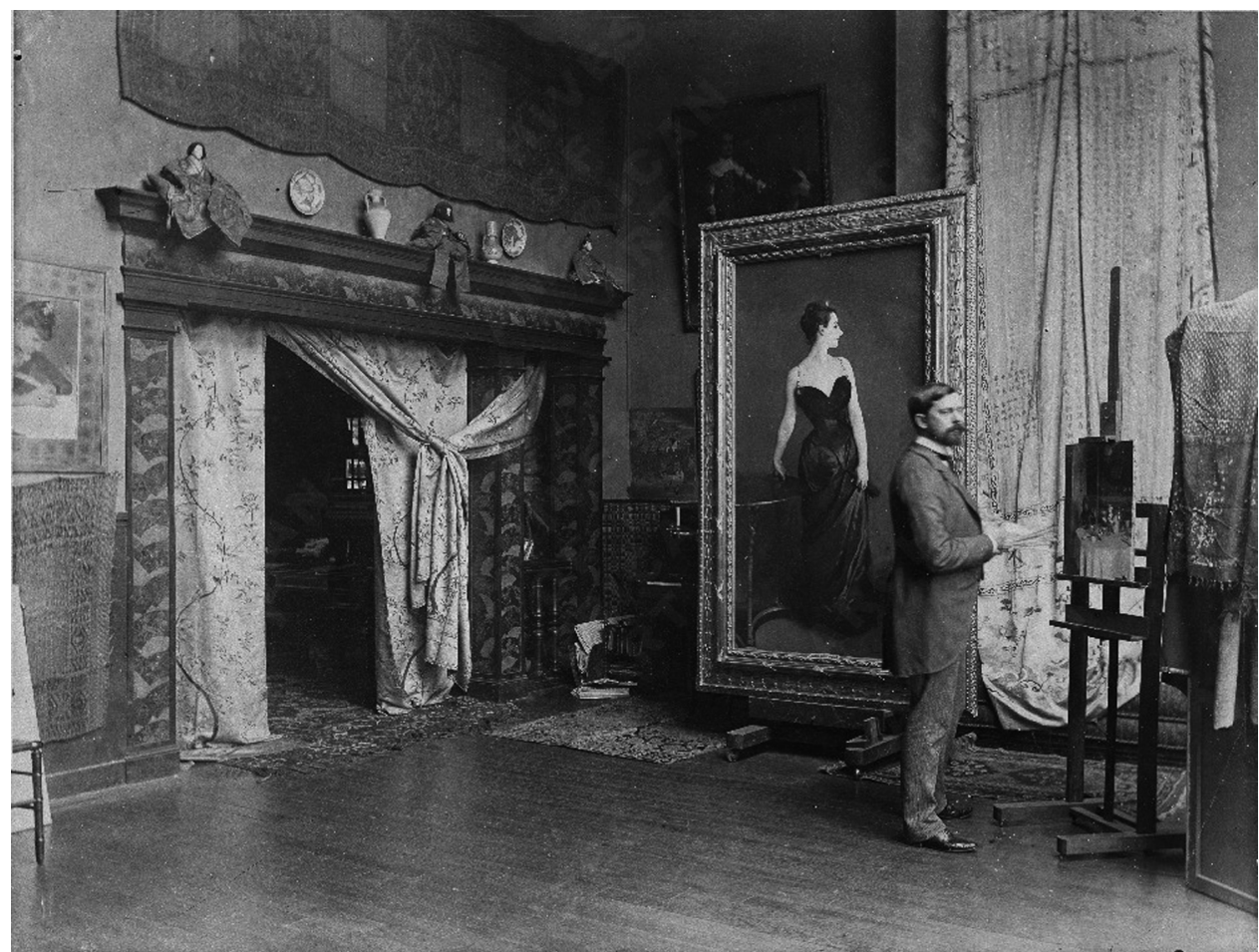

Fig. 2. Auguste Giraudon. John Singer Sargent en su estudio 41 boulevard Berthier de París, ca. 1884. Smithsonian Archives of Art American.

Los tapices, por su parte, denotan el afán coleccionista y de connaiseur del pintor, un rasgo distintivo que los acercaba a determinadas prácticas propias del coleccionismo de la aristocracia de otros tiempos. A su derecha un pequeño lienzo en el caballete en el que podemos apreciar un escena de interior naturalista, una mujer sentada a la mesa tomando su almuerzo, al otro lado su obra maestra, su tarjeta de visita como artista de renombre, la obra que le dio fama y reconocimiento, Madame $X^{14}$, una obra que suscitó expectación y polémica entre el público y la crítica y que representaba a una conocida dama de la alta sociedad parisina, Madame Pierre Gautreau, en una poco ortodoxa posición en el género del retrato, con el torso ladeado, la cara semioculta y un enorme contraste entre el color negro del vestido y el blanco lechoso de la piel.

Más allá de las cuestiones meramente plásticas, quizás uno de los rasgos que más definían al pintor chic y cosmopolita era el de su papel de retratista de la alta sociedad a la que pertenecían. No en vano el siglo XIX se perfila como el siglo en el que el género del

${ }^{14}$ John Singer Sargent. Madame X. 1883-1884. Óleo/lienzo, 208’6 x 109'9 cm. Metropolitan Museum of Art. New York. 
retrato experimenta un nuevo auge, hecho debido a la enorme demanda proveniente de toda una incipiente burguesía enriquecida que de alguna manera pretendía emular los hábitos de la vieja aristocracia; pero así mismo por el proceso de construcción individual que llevó parejo el desarrollo del capitalismo liberal (Wharman, 2004).

Y no deja de ser paradigmático que aquellos artistas que han pervivido en nuestro imaginario como artistas cosmopolitas y de éxito de la época como John Singer Sargent, Joaquín Sorolla, Raimundo Madrazo, León Bonnat o Giovanni Boldini entre otros, fueran al mismo tiempo aquellos que contribuyeron a crear la imagen plástica que hoy perdura de la burguesía finisecular.

Santiago Rusiñol dio buena cuenta también de la figura del pintor cosmopolita en sus crónicas parisinas del periódico La vanguardia. El relato del periplo que le llevó a él y al círculo de amigos catalanes en París, al estudio de un artista de renombre en la época o como el definió Un pintor chic (Rusiñol, 1891, 4) es un excelente reflejo del artista cosmopolita de la época y nos sirve así mismo para obtener un testimonio directo sobre los modos de aprehensión de la realidad por parte de sus propios protagonistas.

El desplazamiento urbano con el que comienza la crónica constituye ya uno de los rasgos diferenciales de ese modelo artístico cuyas prácticas contrastan con las del submundo Montmartriano. El artista en cuestión, al que se refería Rusiñol, recibía todos los jueves las visitas de compromiso en su villa estilo neorenacimiento. Vestidos con lo mejor que se tiene en lo más hondo del baúl, durmiendo entre el alcanfor y pimienta (Rusiñol, 1891, 4), Rusiñol y su troupe se adentraron en el interior del salón para contemplar el despliegue del artificio: creyendo oportuno el momento de enseñar su obra al público escogido, tocó una campanilla que hizo comparecer a dos criados con un gran cuadro oculto tras de un tapiz de Gobelinos. Corrióse aquella cortina con grandioso espectáculo y vimos, por fin, la obra deseada. El público respondió con aplausos y alabanzas a la mise en scène, nuestros artistas bohemios, sin embargo, respondieron con profunda decepción pues ni el tema ni la factura de la obra presentaban nota alguna de originalidad.: El efecto que nos hizo aquella casa, aquellas obras, aquel público, aquel artista, fue frío como un invierno sin fuego; tan frío que tuvimos que salir y pisar la nieve por la calle y subir la nevera de Montmartre para hacer entrar en reacción nuestro espíritu.

En todo ese despliegue que se repetía cada jueves por la tarde se manifiestan muchos de los aspectos que definieron la prácticas del pintor cosmopolita, la afectación y el despliegue teatral, constituían los recursos para adquirir renombre y proyección social, condición sine qua non para ser aclamado.

El último tipo de pintor al que se refería el cronista de La Ilustración Artística era el pintor ligado a la pintura mercantil: Hay también los mercantiles, por decirlo así; aquellos para quienes el lienzo o el mármol no son sino cañamazos en los cuales están siempre dispuestos a bordar el asunto de encargo, el tema en boga, el pensamiento ajeno, sin más mira que la remuneración presente y el mayor precio en lo futuro (X., 1899, 911, 379).

\section{EL PINTOR COMERCIAL}

El 3 de mayo de 1852 el pintor y grabador Honoré Daumier publicaba en la revista satírica francesa Le Charivari una ilustración que formaba parte de la serie titulada "Le public du Salon". La serie reproducía periódicamente las impresiones del pintor sobre los 


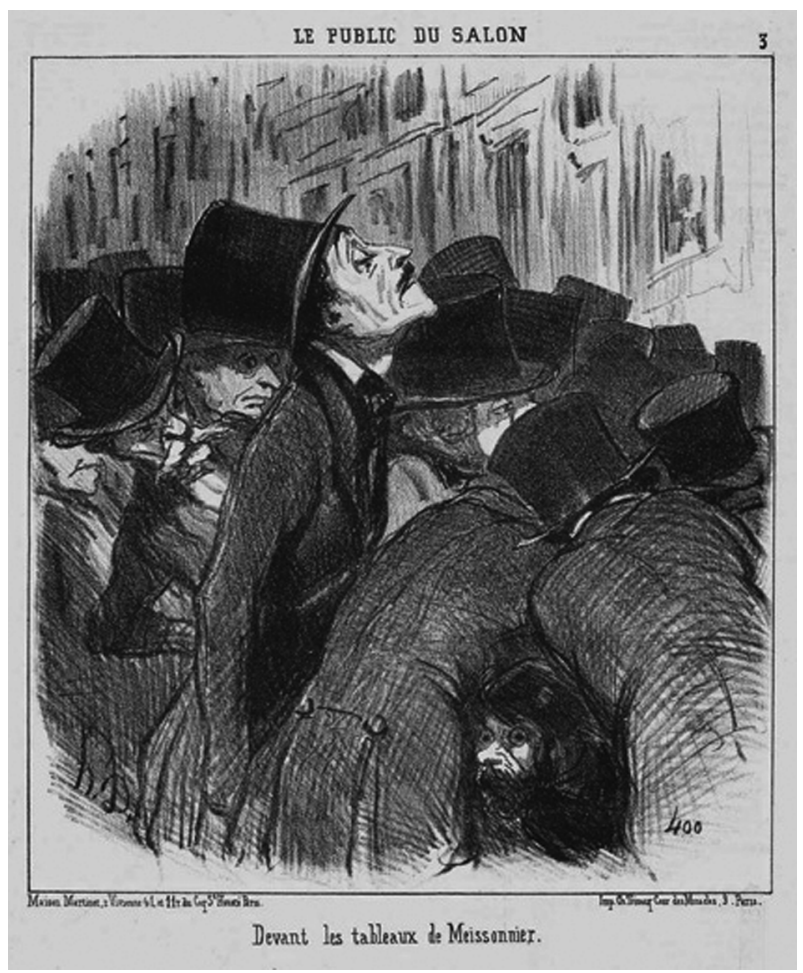

Fig. 3. Honoré Daumier. Devant les tableaux de Meissonier. 1852, 33’7 x $26 \mathrm{~cm}$. Litografía coloreada.

certámenes del Salón de Bellas Artes francés que se celebraba en París anualmente en lo que constituye uno de los documentos gráficos que mejor han descrito al público del arte del siglo XIX.

La ilustración representaba a un grupo de hombres que se estrujaba y abalanzaba frente a un indeterminado cuadro imposible de discernir. El gesto inquisitivo y crítico de uno de ellos nos transmite una sensación de minucioso y constante análisis. Como por arte de magia Daumier dibuja una cabeza que sobresale de entre las cinturas del público arremolinado, una especie de fantasma que guarda un enorme parecido con la figura de un pintor de la época que gozó de enorme popularidad pero que fue denostado y admirado a partes iguales entre los entendidos y diletantes del arte, nos referimos a Ernest Meissonier.

Efectivamente, de todos los artistas de la época aquel que acumuló las mayores iras de los críticos de arte, que no del público ${ }^{15}$, fue Ernest Meissionier, condenado por algunos de sus contemporáneos por considerársele el artista que más explotó los mecanismos del arte comercial. Algunos de los apelativos que recibió en la época lo definían como: le geant des nains, le grand peintre du microcosme o le peintre ordinarie du roi de Lilliput en

15 Para más información sobre el tema de la reputación artística véase (Furió, 2012). 
referencia al tamaño de sus lienzos, un aspecto, el de las dimensiones de las pinturas que junto con el género, constituía el rasgo diferencial de la pintura comercial ${ }^{16}$.

Contar con un Meissonier en una colección era un lujo al que muy pocos podían acceder, no en vano el propio Capitan Nemo en la pinacoteca del Nautilus contaba uno entre las obras de su colección ${ }^{17}$, en un claro ejemplo representacional del gusto de la época. Se han vinculado, así mismo, a las obras de Meissonier con un nuevo perfil social de coleccionista, proveniente de los sectores sociales de la incipiente burguesía, con capacidad adquisitiva pero sin formación artística. Una antítesis del connaiseur del siglo XVIII. En ese sentido y tal y como afirmaba Émile Zola era la obra aquello que adquiría valor; la obra y la firma como garantía de la mercancía, un aspecto que Svetlana Alpers (Alpers, 1996) atribuyó como iniciador a la figura de Rembrandt.

El paso del tiempo no contribuyó a mejorar la consideración de este artista pues la historia del arte le ha deparado un sombrío lugar. Todo ello nos hace cuestionarnos sobre los criterios que en el siglo XIX hacían a un artista merecedor de consideración entre dos entidades sociales como el público y los entendidos del arte y en definitiva de los recelos que despertaba entre determinados sectores la pintura comercial.

A lo largo de la historia los artistas han ejercido la pintura como profesión y han obtenido unos réditos económicos por el desempeño de la misma. Es obvio, por tanto, que los artistas han estado vinculados a la práctica comercial por más que la Academia se erigiera como antítesis del principio mercantil. Y es cierto, así mismo, que los artistas a lo largo de la historia desarrollaron estrategias sobre la rentabilidad económica de la producción artística. Obtener el máximo beneficio de una obra fue un aspecto casi inherente al mismo proceso de producción. El propio Vasari, fue consciente de la necesidad de economizar los procesos de producción artística, reduciendo la duración de la ejecución de una obra, potenciando precios bajos, primando la puntualidad de las entregas, así como conformando un equipo de colaboradores eficaces que ayudaran en la realización. La mayor rapidez en la elaboración de la obra y por tanto su menor coste económico es uno de los aspectos modernos que añadió Vasari al Proemio de la segunda edición de 1568 de su obra Le Vite.

La creación de la Academia en el siglo XVII y la codificación de las Bellas Artes acaecida en el siglo XVIII, contribuyeron, sin embargo, a separar el criterio económico y utilitario de la práctica artística, cuya única vocación respondería, a partir de entonces, a la delectación. Desde el pensamiento académico se condenaba por encima de cualquier precepto el alejamiento de los principios de idealidad del arte inherentes al sistema académico y se despreciaba a aquellos artistas que comerciaban con sus obras, tildándolos de pintores comerciales, quizás una de las mayores ofensas que un artista podía recibir.

Este desprecio perduró a lo largo del siglo XIX, sin embargo, los motivos que fundamentaron las críticas que se ejercieron en un periodo u en otro descansaban en lógicas diferentes. Si durante el siglo XVIII aquello que se cuestionaba de la pintura comercial era

16 Se denominaba tableutin a las pequeñas obras de pintura, ya fueran lienzo o tabla, que ilustraban escenas de géneros menores, principalmente escenas de casacón, inspiradas en los tipos de los siglos XVII y XVIII, fruto de la moda desatada en la época por la aparición de la obra Los tres mosqueteros de Alejandro Dumas; pero también asuntos orientalistas o costumbristas. En la mayoría de los casos los tableutins presentaban una factura preciosista y minuciosa que pudiera condensar en la escasa superficie las dotes del pintor.

17 Entre las obras de pintura moderna, había cuadros firmados por Delacroix, Ingres, Decamps, Troyon, Meissonier, Daubigny, etc. (Verne, 2003, 123-124). 
su alejamiento de los preceptos de idealidad y la función estética del arte, en el siglo XIX las críticas se encaminaron hacia la pérdida de la originalidad que conllevó la pintura comercial y sus artífices como responsables de dicha pérdida.

Uno de los autores que mayor desconsideración esgrimió contra los pintores comerciales del siglo XIX fue el escritor Émile Zola. Inmerso en su cruzada por la pintura naturalista, Zola consideraba que los artistas que osaban practicar la pintura de carácter comercial devolvían el arte a su estado primigenio, algo inconcebible pues la relación arte-artesanía era, en los tiempos que corrían, en modo alguno equiparable ${ }^{18}$.

Quizás aquello que más perturbaba la mente de los puristas del arte por el arte, fuera el proceso de profesionalización del artista, violando los preceptos conquistados ya en el Renacimiento sobre la creatividad o inventiva artística que hundían sus raíces en la ( $\Phi v \sigma \iota \varsigma)$ physis griega (Kris y Kurz, 2002, 64) y que habían sido elevados a categoría máxima nuevamente en el Romanticismo.

Todas estas reacciones no hacían sino dejar al trasluz los mecanismos sobre los cuales se construyó el basto proyecto artístico de la modernidad. Un proyecto sustentado en la máxima de la originalidad como premisa fundamental, originalidad entendida como aquello que provenía de la inventiva de un autor y que otorgaba, por tanto, carácter excepcional. Estrategias, no obstante, que la historiografía posmoderna ha contribuido a desacralizar (Krauss, 2000).

Ello implicaba, además, una herejía aún mayor, la pérdida del aura, y la destrucción de la unicidad, aspecto que redundaba nuevamente en la ausencia de originalidad.

Efectivamente, el siglo XIX, desarrolló toda una serie de prácticas artísticas que convinieron a economizar los procesos de producción y comercialización artística. El desarrollo de las nuevas técnicas reproductivas de la imagen, acaecidas en el siglo XIX conllevaron un trastorno que obligó, principalmente, a la pintura a repensar su carácter como disciplina visual. Más allá de los conflictos entre partidarios y detractores de la reproducción artística, aquello que condicionó las prácticas artísticas de la época, tal y como reseñó Walter Benjamin en su canónica obra El arte en la época de la reproductibilidad técnica (Benjamin, 2003), fue la desaparición de la categoría de unicidad y la pérdida de ese valor inmanente de las obras de arte denominado aura. Las nuevas prácticas acometidas por los marchantes y casas de edición artísticas, como se empezaron a denominar, desarrollaron toda una serie de técnicas que permitían la reproducción múltiple de una pintura $^{19}$. Por un lado se obtenía beneficio de la venta del original, del cual se elaboraban co-

18 La peinture, ainsi envisagée, devient une sorte d'ébénisterie [...] Eh! Non, monsieur, vous n'avez pas fait un tableau. C'est là, si vous voulez, une image habile, un sujet plus ou moins spirituellement traité, une marchandise à la mode. Mais jamais une ébéniste ne croit avoir fait une oeuvre d'art lorsqu'il a établi élégamment et marqueté un petit meuble de Salon. Vous êtes cet ébéniste; vous savez à merveille votre métier; vous avez dans le doigts une habilité prodigieuse. Voilà votre talent d'ouvrier (Zola, 1991, 185).

19 Probablemente fue la casa del editor y marchante Adolphe Goupil quien mejor ejemplificó el nuevo mercado del arte con la utilización de técnicas como el fotogliptio, el tipograbado o el cromotipograbado, entre otras. En 1867 la empresa compró el derecho de explotación para Francia de la técnica o procedimiento Woodbury, también conocida como fotogliptio, ésta evitaba que las imágenes se alteraran con la luz gracias a ello se podía realizar un gran número de imágenes de mejor calidad en poco tiempo. La diáfanografía será otra de las técnicas que empleará la Casa Goupil, consistente en realizar una reproducción de la obra sobre vidrio, de tal forma que pudiera servir a modo de vidriera. A partir de 1873 la Maison Goupil adoptará la técnica del fotograbado. En 1882 la empresa empleará una nueva técnica, el tipograbado al que años después se sumará el cromotipograbado. 
Fig. 4. Ernest Meissonier en su estudio de verano en Poissy, ca. 1860.

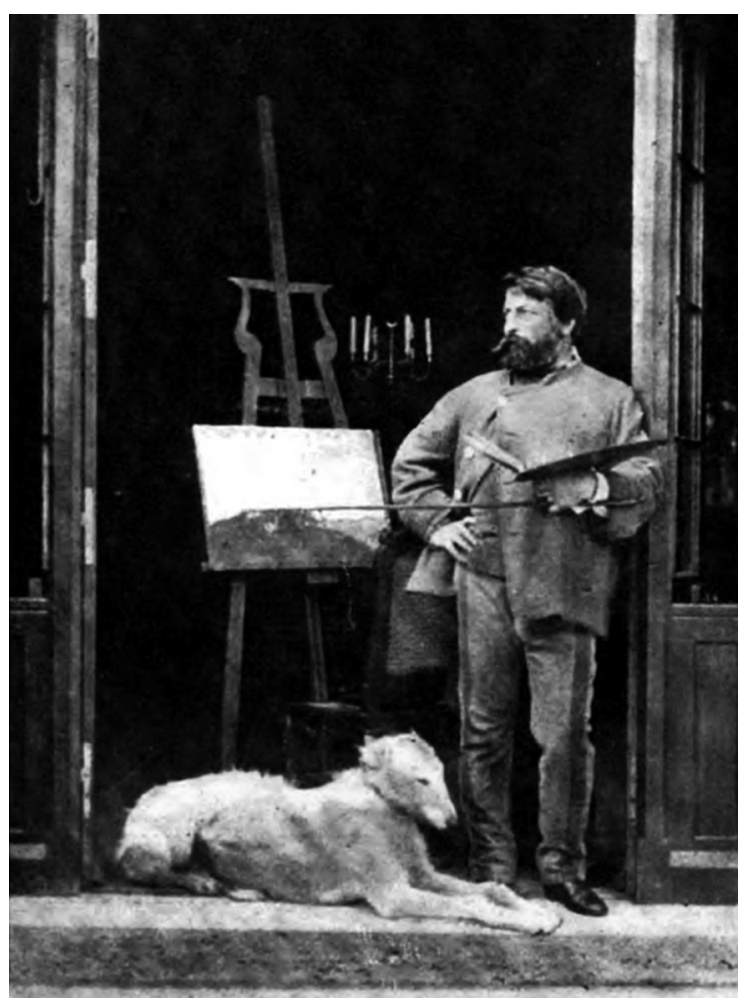

pias seriadas que luego serían así mismo vendidas y finalmente se obtenían beneficios en concepto de propiedad intelectual por explotación de la imagen ${ }^{20}$.

Si Meissonier se convirtió en el blanco de las críticas de numerosos críticos de arte y diletantes fue precisamente porque observaron en él más que en ningún otro artista de la época la práctica de la (re)producción pictórica comercial. Una práctica definida por la producción de obras de manera seriada, con temas recurrentes adaptados al gusto del público y que presentaban escasas variaciones formales unas de otras. Ello sin embargo, no incidió en el hecho que las pinturas de Meissonier fueran de las más demandadas en la época y que en 1890 fundara junto Auguste Rodin y Puvis de Chavannes un nuevo espacio expositivo, el Salon de la Société Nationale de Beaux Arts, para escapar de las restricciones autoritarias del académico Salon de Beaux Arts, un nuevo salón con un perfil más comercial auspiciado por la aportación económica de amateurs del arte y de coleccionistas como Moïsse Camondo.

${ }^{20}$ La reproduction d'une oeuvre d'art a de multiples fonctions et usages: assurer une pérennité, diffuser l'art en le mettant à la disposition de chacun, contribuer à la notoriété des peintres, décorer les intérieurs, enseigner, et permettre à toute une catégorie d'artistes de subsister (Lafont-Couturier, 2000, 29). 


\section{CONCLUSIÓN}

Estas páginas pretendían exponer las distintas concepciones artísticas que habitaban en los espíritus de los pintores de la época y las respuestas que éstos generaban en el imaginario social. Pintores que hipotecaban su juventud poniendo en riesgo, en ocasiones, su salud física y mental, enajenándose de la vida acomodada y burguesa, temporal o definitivamente, para entregarse a un ideal artístico y a la llamada vocacional, pintores de moda que se codeaban con la alta sociedad, agasajados por la oficialidad artística de las instituciones, que gozaban de los elogios de público y crítica y cuya posición social era el lugar al que la mayoría de pintores anónimos de la época ansiaba alcanzar, pintores que practicaban un oficio y rentabilizaban sus obras, produciendo obras por encargo y seriadas para poder vivir con mayores o menores lujos.

Modelos que como observamos desarrollan algunos de sus aspectos, con anterioridad y se proyectan en el tiempo diacrónicamente para conformarse en tipologías.

Perfiles y prácticas sin fronteras visibles que nos ofrecen la mayoría de las veces actitudes que denotan la especificidad de cada experiencia vital, entre la norma y la excepción, entre les capacités inventives des individus ou des communautés et les contraintes et les conventions qui limitent (Chartier, 1998, 96-97); actitudes que transitan ocasionalmente de un modelo a otro, de una práctica a otra y que nos ofrecen la riqueza de las prácticas humanas y nuestras concepciones culturales.

Entre esas actitudes que caracterizaban cada una de las respuestas frente a la práctica artística y la consideración social que de ellas proyectaba la sociedad, en ese diálogo cuya causalidad es difícil de determinar, se inserta el ámbito de construcción de los modelos culturales.

¿Cómo se veían las personas, unas a otras, cómo se representaban a sí mismas ante los otros, y a los demás ante sí mismas? ¿Cómo se imaginaban los contornos de la sociedad parisina, cómo comprendían su posición social y espacial y las transformaciones radicales que se estaban produciendo? ¿Cómo se trasponían, utilizaban y modelaban estas representaciones en la retórica del discurso político? Éstas son preguntas importantes y fáciles de hacer, pero correosas de responder (Harvey, 2008, 343).

\section{BIBLIOGRAFÍA}

ALPERS, S. (1996): El taller de Rembrandt. La libertad, la pintura y el dinero, Madrid, Mondadori, $183 \mathrm{p}$.

BENJAMIN, W. (2003): El arte en la época de la reproductibilidad técnica, México, Ítaca, 113 p.

BOURDIEU, P. (1995): Las reglas del arte. Génesis y estructura del campo literario, Barcelona, Anagrama, $250 \mathrm{p}$.

COMPANY, X. (1991): L'Art i els artistes al País Valenciá Modern (1440-1660), Barcelona, Curial $337 \mathrm{p}$.

CHARTIER, R. (1998): Au bord de la falaise. L'histoire entre certitude et inquietudes, París, Albin Michel, $379 \mathrm{p}$.

CHARTIER, R. (2002): El mundo como representación: estudios sobre historia cultural, Barcelona, Gedisa, 288 p.

D’ENNERY, A. y GRANGÉ, E. (1843): “Les Bohémiens de Paris”, Le Magasin théâtral: Choix des pièces nouvelles jouées surtous les théatres de Paris, 36, 1-43. 
FOUCAULT, M. (2003): Historia de la Sexualidad. La inquietud de sí, vol. 3, Argentina, Siglo XIX, $272 \mathrm{p}$.

FURIÓ, V. (2012): Arte y reputación, Barcelona, Servei de Publicacions de la Universitat de Barcelona, $248 \mathrm{p}$.

GIEDION, S. (2009): Espacio, tiempo y arquitectura, Barcelona, Reverté, 857 p.

GOLFIER, M. y WAGNEUR, J.D. (2000): Émile Goudeau. Dix ans de bohème [1888], París, Champs Vallon, $286 \mathrm{p}$.

HARVEY, D. (2008): París, capital de la modernidad, Madrid, Akal, 458 p.

HAUSER, A. (2009): Historia social de la literatura y el arte, Vol. II, Madrid, De bolsillo, 544 p.

KRAUSS, R. E. (2000): La originalidad de la vanguardia y otros mitos, Madrid, Alianza, 320 p.

KRIS, E. y KURZ, O. (2002): La leyenda del artista, Madrid, Ensayos Arte Cátedra, 136 p.

LAFONT-COUTURIER, H. (2000): "M. Gérôme travail pour la maison Goupil", en: Lafont-Couturier, H. (Ed.), Gérôme et Goupil. Art et entreprise, Catálogo Exposición, Bordeaux, Musée Goupil, 12 octobre 2000 - 14 janvier 2001, París, Réunion des Musées de Nationaux, 13-30.

LA GORCE de, J. (Ed.) (1985): La condition sociale de l'artiste, Saint-Étienne, C.N.R.S, Université de Saint-Étienne, $135 \mathrm{p}$.

MAYAYO, P. (2003): Historia de mujeres, historia del arte, Madrid, Cátedra, 174 p.

MONTHIAS, J.M. (1996): Le marché de l'Art aux Pays-Bas XV-XVIIe siècles, París, Flammarion, $191 \mathrm{p}$.

MURGUER, H. (1988): Scènes de la vie de bohème [1851], París, Gallimard, 480 p.

PINO, P. (1954): Dialogo di Pittura [1548], Milán, Rizzoli, 99 p.

POLANYI, K. (1981): La Gran transformación. Crítica del liberalismo económico, Madrid, La Piqueta, $466 \mathrm{p}$.

PYAT, F. (1834): "Les artistes", Nouveau tableau de Paris au XIX siécle, IV, 1-21.

RUSIÑOL, S. (1892): "Desde el molino. Ramón Canudas”, La Vanguardia, 27-10, 4-5.

RUSIÑOL, S. (1891): "Desde el molino. Un pintor chic”, La Vanguardia, 01-01, 4-5.

SEIGEL, J. (1991): Paris bohème, 1830-1930, París, Gallimard, 419 p.

SCHWARTZ, V. (1999): Spectacular Realities: Early Mass Culture in Fin-de-siècle Paris, Berkeley, $243 \mathrm{p}$.

VASARI, G. (1832-1838): "Vita di Bastiano detto Aristotile", Le opere di Giorgio Vasari. Pittore e architetto aretino, Parte II, David Passigli e socj, Firenze, 1496 p.

VERNE, J. (2003): Veinte mil leguas de viaje submarino, Madrid, Alianza, 560 p.

WEBER, M. (1985): La ética protestante y el espíritu del capitalismo, Barcelona, Orbis, 227 p.

WHARMAN, D. (2004), The making of the Modern Self: Identity and Culture in Eighteenth century England, New Haven, Yale University Press, 432 p.

WHITE, H. у C. (1992): La carrière des peintres au XIXe siècle, París, Flammarion, 280 p.

X. (1899): "Los Salones de París de 1899”, La Ilustración Artística, no 911, 379.

ZWEIG, S. (2008): El misterio de la creación artística, Madrid, Sequitur, 112 p.

ZOLA, É. (1991): Écrits sur l'Art [1866-1896], París, Gallimard, 532 p. 
